\title{
SIERRA RODRÍGUEZ, Javier: La participación en la elaboración de normas de la Administración General del Estado
}

\section{SIERRA RODRÍGUEZ, Javier: La participación en la elaboración de normas de la Administración General del Estado}

\author{
Milagrosa Bascón Jiménez \\ Universidad de Córdoba (España) \\ ORCID: https://orcid.org/0000-0003-0678-0282 \\ mbascon@uco.es
}

\section{NOTA BIOGRÁFICA}

Doctora en CC. Económicas (Metodología y análisis del desarrollo regional) y Licenciada en Ciencias Políticas y Sociología, actualmente es Profesora de Sociología de la Universidad de Córdoba. A lo largo de su trayectoria ha participado en congresos internacionales y cuenta con estancias de investigación en Portugal y Colombia. Sus líneas de investigación están relacionadas con las políticas públicas, la educación y la familia.

\section{RESUMEN}

Reseña del libro de Javier SIERRA RODRÍGUEZ, La participación en la elaboración de normas de la Administración General del Estado. Madrid, Centro de Estudios Políticos y Constitucionales, 2019, 271 págs. Este libro se centra en la evaluación de la participación ciudadana a través del trámite de consulta previa y de audiencia e información pública en la elaboración de reglamentos y de proyectos de Ley en el ámbito de la Administración General del Estado. Se analizan los mecanismos y el ejercicio de la participación, confrontando las percepciones de técnicos de la administración y de los participantes.

\section{PALABRAS CLAVE}

Participación; normas; mejora regulatoria; gobierno abierto.

\begin{abstract}
Review of Javier SIERRA RODRÍGUEZ, Participation in the elaboration of norms of the General State Administration. Madrid, Centro de Estudios Políticos y Constitucionales, 2019, $271 \mathrm{pp}$. This book focuses on the evaluation of citizen participation through the process of prior consultation and the audience and public information in the development of regulations and bills in the field of the General State Administration. The mechanisms and the exercise of participation are analyzed, confronting the perceptions of administration technicians and participants.
\end{abstract}

\section{KEYWORDS}

Participation; law; better regulation; open government.

Nos encontramos en una época caracterizada por estar inmersos en continuos procesos de cambio que una y otra vez ponen en duda los mecanismos propios del sistema político moderno. Esta puesta en cuestión se refleja en una ciudanía que solicita su espacio para expresar sus inquietudes y su opinión ante 
REALA. Nueva Época - N. 14, octubre 2020 - ISSN: 1989-8975 - DOI: https://doi.org/10.24965/reala.i14.10805 - [Págs. 201-204]

Sierra Rodríguez, Javier: La participación en la elaboración de normas de la Administración General del Estado

Milagrosa Bascón Jiménez

los acontecimientos políticos y sociales. Como reacción a las nuevas demandas ciudadanas hay un debate abierto sobre la mejor manera de recuperar la confianza ciudadana (Villoria e Izquierdo, 2015; Llera, 2016; Valencia y Canales, 2018), y en este proceso, las administraciones públicas están abriéndose a la ciudadanía, dejando entrar a la sociedad civil en el marco de su funcionamiento y adoptando cambios para hacer más permeable y transparente su actuación.

De todos los modos de participación, el libro se centra en aquella que se produce en torno a la producción normativa cuyas atribuciones corresponden al poder ejecutivo del Estado, es decir, a la elaboración de las normas reglamentarias que puede aprobar el Gobierno y de los proyectos de Ley que posteriormente se remiten al parlamento. Tradicionalmente ha existido un trámite de audiencia en el proceso de elaboración de reglamentos, consistente en invitar a la realización de alegaciones sobre los borradores de normas a las organizaciones representativas. Tras una evolución hacia la mejora regulatoria que ha estado influenciada por la UE y por la OCDE, se ha pasado a un sistema en el cual los procedimientos de participación son más abiertos y se llevan a cabo a través de cauces online en los que cualquier ciudadano puede acceder a la información y participar, sea o no un potencial afectado por la norma ${ }^{1}$. Así, el texto nos aproxima a lo largo de sus diez capítulos y de una manera detallada a la consulta pública, previa a la existencia de un borrador de norma, y al trámite de audiencia e información pública, que se produce cuando ya se tiene un texto articulado.

Los tres primeros capítulos del libro establecen los objetivos y el marco jurídico, conceptual y metodológico. El autor hace alusión a las diferencias existentes en torno al concepto de participación, haciendo una distinción entre los trámites de la vieja participación -principalmente presencial y sujeta a la condición de interesado-; y la nueva participación, orientada al ciudadano y con un enfoque que minora la mediación de asociaciones representativas, y que se desarrolla de manera más ágil a través de los cauces de comunicación online. Enfrenta, de alguna manera, la administración burocrática con una administración receptiva de demandas sociales propia del siglo XXI. También, contextualiza la realidad de la producción normativa de la AGE, haciendo un recorrido por los cambios legislativos en materia de participación y la impronta del proceso hacia una better regulation, destacando la importancia de la actuación del ejecutivo del Estado, al que corresponde la aprobación de las normas reglamentarias y que suponen más del $90 \%$ de las que se publican anualmente.

A partir de ahí, se formula como objetivo la evaluación de la participación en estos trámites en el ámbito de la AGE, y se detalla la metodología utilizada mediante la combinación de técnicas cuantitativas y cualitativas, elaborando un censo de 694 procedimientos de participación, aplicando encuestas y desarrollando entrevistas en profundidad para obtener datos reales y percepciones de los actores implicados: particulares y organizaciones participantes (CEOE, AECC, Consejo General de la Abogacía, entre otros) y técnicos de la AGE de todos los Ministerios. Cabe destacar en este apartado la dificultad que encuentra el autor para extraer información procedente de los técnicos de la administración debido al discurso corporativo de la administración, por lo que adquiere mayor relevancia su contraste a través de la percepción de los participantes en estos procesos.

A partir del capítulo 3 se exponen los datos obtenidos, cuantificando el número de trámites participativos y analizando críticamente su configuración. La investigación detectaba una media de cincuenta procesos participativos al mes, aunque el ritmo de celebración no es algo uniforme en el tiempo, porque en última instancia depende de los ciclos de estabilidad y dinamismo gubernamental. Además, el autor detecta una amplia asimetría entre los ministerios de producción normativa -que consecuentemente acaparan la mayoría de los procedimientos-, y aquellos otros ministerios que apenas tienen trámites participativos porque tampoco producen normas, o porque las tramitadas están dentro de los supuestos de excepción. Bajo la estructura ministerial vigente durante la investigación, el $43,9 \%$ de los procesos de participación correspondían al Ministerio de Pesca, Alimentación y Medioambiente y un 11,8\% al Ministerio de Sanidad, Servicios Sociales e Igualdad, quedando el resto de ministerios con un equivalente menor al $10 \%$ de los procesos de participación.

Entre los aspectos problemáticos detectados inicialmente, destaca la desnaturalización de la consulta previa. La lógica de este tramite es obtener contribuciones sin disponer de predeterminaciones iniciales e incluso poder optar por soluciones no regulatorias, pero sigue manteniendo la inercia de la administración a trabajar con borradores de normas antes de la celebración de la consulta, lo que tiene como consecuencia un encorsetamiento de las aportaciones. Otro aspecto problemático es la aplicación de las excepciones y

Esta configuración se estableció con carácter general por la Ley 39/2015, de 1 de octubre, del Procedimiento Administrativo Común de las Administraciones Públicas y específicamente en la Administración General del Estado se proyecta a través del artículo 26 de la Ley 50/1997, de 27 de noviembre, del Gobierno (redacción otorgada por la Ley 40/2015, de 1 de octubre). 
REALA. Nueva Época - N. 14, octubre 2020 - ISSN: 1989-8975 - DOI: https://doi.org/10.24965/reala.i14.10805 - [Págs. 201-204]

Sierra Rodríguez, Javier: La participación en la elaboración de normas de la Administración General del Estado

la inseguridad que causa a los técnicos responsables de los expedientes normativos por el riesgo de ligitiosidad y ante una incorrecta interpretación de los supuestos de aplicación. Este capítulo se cierra dejando constancia de la detección de cauces habituales de relación informal entre organizaciones y la AGE durante los procesos de elaboración normativa, así como de la celebración habitual de reuniones.

El capítulo 5 ofrece un panorama de la participación en el que son las asociaciones y organizaciones las que verdaderamente ejercen la participación. Es importante señalar que el concepto de participación ciudadana en su concepción más actual (participación de la ciudadanía activa) no se contempla en estos casos. Estamos hablando de particulares y organizaciones con intereses muy concretos, con un predominio de las segundas como protagonistas de la participación. Además, los particulares no solo tienen una presencia escasa, sino que tampoco responden a un perfil corriente, porque la regla general es que se trata de profesionales o expertos relacionados con la materia. Rara vez se observa que participen ciudadanos corrientes. Las únicas excepciones se producen cuando las asociaciones u organizaciones a las que pertenecen movilizan a sus asociados para hacer alegaciones ante una norma que les resulta de especial interés o lesiva para sus intereses. Por otra parte, la presencia de expertos convocados como tales no se produce con carácter general en torno a los dos trámites de referencia, sino que se detecta ante normas muy técnicas en fases anteriores, o bien, se canaliza su participación a través de los órganos consultivos en los que puedan tener presencia.

En cualquier caso, se aprecia que existe una participación desigual que depende en su gran medida del tipo de norma sobre la que se está trabajando y el sector al que afecta. Hay más participación en normas de alcance general. Aparte, la participación es mayor si el sector cuenta con un tejido de asociaciones organizadas que conocen el funcionamiento de la administración y mantienen una interlocución constante.

Los capítulos 6 y 7 se centran en la difusión de los procedimientos y su gestión interna. En términos generales, la difusión queda restringida a lo que obliga la Ley del Gobierno y las instrucciones del Consejo de Ministros para habilitar la participación ${ }^{2}$. Se publican los procedimientos en la web de cada ministerio, en el punto de acceso general y en el portal de transparencia, pero con presentaciones divergentes, no tan intuitivas como requieren los sistemas orientados a los ciudadanos corrientes y sin incluir todas las prestaciones que se especifican en las instrucciones aludidas (ej. buscadores de procedimientos). Según el diagnóstico, todo lo que vaya más allá de lo que exige la norma no se lleva a cabo salvo casos puntuales. Es decir, no hay una proactividad para promover el conocimiento público de estos cauces y de los procedimientos mediante herramientas sencillas como son las redes sociales o los sistemas de suscripción a alertas para avisar de la apertura de los trámites. Aparte, las comunicaciones expresas se limitan a las organizaciones representativas como tradicionalmente se ha estado haciendo antes de la configuración dada a la participación por las leyes 39 y 40/2015.

Sobre la gestión interna, se detecta la disparidad existente en cada departamento ministerial, que tiene como consecuencia que haya diferencias sustantivas en la forma de presentar y configurar el ejercicio de la participación a través de las páginas web de cada ministerio, pero también en la forma de reflejar la participación en las Memorias del Análisis de Impacto Normativo. Según el autor, esta divergencia entre ministerios es una barrera a la adopción de un modelo más orientado al ciudadano, porque precisa en primer lugar una homogeneidad y características comunes que no dificulten o confundan al ciudadano que busca estos procedimientos.

En el ámbito de la gestión interna, también se analiza la visión de los técnicos de la AGE quienes insisten en la valoración minuciosa de todas las alegaciones que llegan, expresando que la realidad de muchas de ellas impide su consideración porque están fuera del objeto de la norma, son contradictorias a la regulación europea o estatal vigente, al reparto de competencias entre niveles de administración o, simplemente, porque son presupuestariamente inviables.

El capítulo 8 contiene la valoración del ejercicio de participación. El texto refleja la percepción diferenciada que los técnicos de la administración otorgan a la utilidad de las aportaciones. En términos de mejora de la producción de normas valoran especialmente las que formulan las organizaciones, porque suelen tener un mayor conocimiento de las materias y un carácter más técnico, mientras que las alegaciones ciudadanas -según sus percepciones- son poco aprovechables sin perjuicio de los beneficios que aporte la posibilidad de participar.

2 Orden PRE/1590/2016, de 3 de octubre, por la se publica el Acuerdo del Consejo de Ministros de 30 de septiembre de 2016, por el que se dictan instrucciones para habilitar la participación pública en el proceso de elaboración normativa a través de los portales web de los departamentos ministeriales. 
La perspectiva de las organizaciones lleva a una valoración positiva de la experiencia de participación (solo un $21,7 \%$ se muestra insatisfecho) en unos procesos que resultan sencillos para nueve de cada diez consultados. Sin embargo, las principales críticas vienen dadas por la insuficiencia de los plazos, la falta de confirmación de la recepción de las alegaciones porque no se acusa recibo, así como por la inexistencia de retorno o de su valoración. Estas carencias producen un desincentivo a la participación y les hace dudar de su utilidad porque se trate de un cumplimiento formal de la regulación sin que exista intención alguna de escuchar a la ciudadanía.

En un extenso capítulo 9, se desarrollan diez líneas de mejora con veintiséis recomendaciones para el perfeccionamiento de los procesos participativos, exponiendo en paralelo buenas prácticas susceptibles de transferencia, muchas de ellas procedentes de las Comunidades Autónomas que han mostrado un amplio dinamismo en la puesta en marcha de procesos de participación (Aragón, País Vasco o Región de Murcia).

Las conclusiones sintetizan los resultados de la evaluación y sobre ellas sobrevuela la idea central de que estos trámites tienen un amplio potencial como herramientas de participación e implicación de la ciudadanía, pero exigen que la administración muestre una mayor proactividad para darlos a conocer, perfeccione y dote de homogeneidad a su presentación pública y simplifique su ejercicio si realmente se quieren orientarlos hacia la ciudadanía. Todo ello sin olvidar, como menciona el autor al final de las conclusiones, la necesidad de ofrecer un retorno a la participación efectuada para que «no quede desprovista de su verdadero sentido».

Tras la lectura del libro, las principales críticas que se pueden mencionar consisten en la necesidad de profundizar en una medición más precisa de la participación en estos procedimientos y en el reto de captar con mayor amplitud la percepción de los particulares participantes. Ambos aspectos derivan de las dificultades del acceso a datos de los expedientes normativos, que el autor señala en el capítulo dedicado a la metodología empleada, y que constituyen retos para futuras evaluaciones de la participación. Aparte, otra observación deriva del enfoque proclive a la participación que es adoptado en el texto, motivo por el que no se adentra especialmente en los riesgos derivados de la actuación de los lobbies y de la posible captura del regulador, si bien han sido examinados por otros autores en obras recientes como el libro de Juli Ponce titulado Mejora de la regulación, lobbies y huella normativa.

Finalmente es conveniente indicar que el libro constituye una de las acciones del Observatorio de la Participación del III Plan de Gobierno Abierto de España y que se ha desarrollado como parte del proyecto de investigación «diagnóstico y evaluación de la participación ciudadana: diseño metodológico y puesta a prueba» del INAP.

\section{BIBLIOGRAFÍA}

LLERA RAMO, F. (2016): Desafección política y regeneración democrática en la España actual: diagnósticos y propuestas. Madrid: Centro de Estudios Políticos y Constitucionales (CEPC).

PONCE, J. (2019): Mejora de la regulación, lobbies y huella normativa. Valencia: Tirant lo Blanch.

VALENCIA, A.; CANALES, J. M. (2018): Estrategias para la calidad y la regeneración de la democracia. Granada: Comares.

VILLORIA MENDIETA, M.; IZQUIERDO SÁNCHEZ, A. (2015): Ética pública y buen gobierno. Regenerando la democracia y luchando contra la corrupción desde el servicio público. Madrid: Tecnos. 